\title{
Nigerian School Children and Mathematics Phobia: How the Mathematics Teacher Can Help
}

\author{
Chinyere F. Okafor ${ }^{1}$, Uche S. Anaduaka ${ }^{2, *}$ \\ ${ }^{1}$ Department of science education, Anambra State University ULI \\ ${ }^{2}$ Department of science and environmental education,University of Abuja \\ *Corresponding author: sanaduaka@yahoo.com
}

Received June 26, 2013; Revised July 24, 2013; Accepted August 05, 2013

\begin{abstract}
This paper considered the importance of mathematics and why it is of utmost necessity that all Nigerian children acquire mathematical knowledge. It noted with dismay the general negative students' attitude towards the subject and their consequent poor performance in it especially in the West African Senior School Certificate Examination (WASSCE). It then looked at the attributes of a mathematics teacher that can bring about a change in the teaching and learning of mathematics and in the attitude of students towards the subject. It finally considered best practices for mathematics instruction, such practices that can stimulate and sustain students' interest in mathematics learning.
\end{abstract}

Keywords: mathematical knowledge, mathematics phobia, poor performance, mathematics teacher, best practices

Cite This Article: Chinyere F. Okafor, and Uche S. Anaduaka, "Nigerian School Children and Mathematics Phobia: How the Mathematics Teacher Can Help." American Journal of Educational Research 1, no. 7 (2013): 247-251. doi: 10.12691/education-1-7-5.

\section{Introduction}

Mathematics is a compulsory subject offered in Nigerian primary and secondary schools and is taught daily in all the schools or at least four times in a week. The first national mathematics curricula for primary and secondary schools used in the country were developed in1979. There was, however, a revision of the secondary curriculum in 1986 to make provision for the 6-3-3-4 (6 years of primary, 3 years of junior secondary, 3 years of senior secondary, 4 years of tertiary) system of education introduced in the country at that time as against the 6-54(6 years of primary, 5 years of secondary and 4 years of tertiary) system that was in existence before then. However, the Universal Basic Education (UBE) programme has been launched as a replacement of the 63-3-4 system in the country. The programme consists of a 9-3-4 system and involves 6 years of primary school and 3 years of junior secondary school culminating in 9 years of uninterrupted schooling. The introduction of the Universal Basic Education (UBE) was a move by the Nigerian Government to strive to attain the Millennium Development Goals and achieve the critical targets of the National Economic Empowerment and Development Strategies (NEEDS) which include value orientation, poverty eradication, job creation, wealth generation and empowering the citizens through education. UBE was launched in the country in 1999.

It therefore became necessary that the existing curricula for primary and junior secondary school be reviewed and updated to fit into the 9-year Basic Education Programme. Hence a New National Mathematics Curriculum for Basic
Education in Nigeria emerged in 2007. Issues that relate to value orientation, peace and dialogue, human rights education, population and family life education, drug abuse, environmental degradation, entrepreneurial and ICT skills as well as HIV/AIDS education were then infused into the relevant contents of the curriculum to make it responsive to the needs of the Nigerian Child and the developmental needs of the country. Also included were quantitative reasoning problems as well as topics like transactions in the home and offices, computer applications, use of measures of central tendency to analyze information on drug abuse, HIV/AIDS and to show the importance of voting.

The Tables below present the common core of the curricula and the associated grade placements.

BASIC EDUCATION MATHEMATICS CURRICULUM. Main Concepts and their Placements

\begin{tabular}{|c|c|c|c|c|c|c|c|c|c|}
\hline \multirow{2}{*}{ Concepts } & \multicolumn{9}{|c|}{ Year Covered } \\
\hline & 1 & 2 & 3 & 4 & 5 & 6 & JS1 & JS2 & JS3 \\
\hline $\begin{array}{l}\text { Number and } \\
\text { Numeration }\end{array}$ & $\sqrt{ }$ & $\sqrt{ }$ & $\sqrt{ }$ & $\sqrt{ }$ & $\sqrt{ }$ & $\sqrt{ }$ & $\sqrt{ }$ & $\sqrt{ }$ & $\sqrt{ }$ \\
\hline Basic Operations & $\sqrt{ }$ & $\sqrt{ }$ & $\sqrt{ }$ & $\sqrt{ }$ & $\sqrt{ }$ & $\sqrt{ }$ & $\sqrt{ }$ & & \\
\hline Measurement & $\sqrt{ }$ & $\sqrt{ }$ & $\sqrt{ }$ & $\sqrt{ }$ & $\sqrt{ }$ & $\sqrt{ }$ & & & \\
\hline Algebraic Processes & & & & $\sqrt{ }$ & $\sqrt{ }$ & $\sqrt{ }$ & $\sqrt{ }$ & $\sqrt{ }$ & $\sqrt{ }$ \\
\hline $\begin{array}{c}\text { Geometry and } \\
\text { Mensuration }\end{array}$ & $\sqrt{ }$ & $\sqrt{ }$ & $\sqrt{ }$ & $\sqrt{ }$ & $\sqrt{ }$ & $\sqrt{ }$ & $\sqrt{ }$ & $\sqrt{ }$ & $\sqrt{ }$ \\
\hline Everyday Statistics & & & $\sqrt{ }$ & $\sqrt{ }$ & $\sqrt{ }$ & $\sqrt{ }$ & $\sqrt{ }$ & $\sqrt{ }$ & $\sqrt{ }$ \\
\hline
\end{tabular}


THE SENIOR SECONDARY MATHEMATICS CURRICULUM. Main Concepts and their placements

\begin{tabular}{|c|c|c|c|}
\hline \multirow{2}{*}{ Concepts } & \multicolumn{3}{|c|}{ Year Covered } \\
\cline { 2 - 4 } & SS1 & SS2 & SS3 \\
\hline Number and Numeration & $\sqrt{ }$ & $\sqrt{ }$ & $\sqrt{ }$ \\
\hline Algebraic Processes & $\sqrt{ }$ & $\sqrt{ }$ & $\sqrt{ }$ \\
\hline Geometry/Mensuration & $\sqrt{ }$ & $\sqrt{ }$ & $\sqrt{ }$ \\
\hline Trigonometry & $\sqrt{ }$ & $\sqrt{ }$ & $\sqrt{ }$ \\
\hline Statistics & $\sqrt{ }$ & $\sqrt{ }$ & $\sqrt{ }$ \\
\hline Probability & & $\sqrt{ }$ & $\sqrt{ }$ \\
\hline
\end{tabular}

Each year presents each concept at a different level.

However, majority of Nigerian school children generally dread mathematics. Most of them consider it difficult, complex and abstract [1]. Worse still, many students do not immediately see the use or applicability of the subject to their lives and to the world of work and so wonder why they should be troubled with the study of the subject. Except as a requirement for admission into institutions of higher learning, most students do not see any other need for mathematics learning.

Unfortunately too, some teachers of mathematics are either not convinced themselves, or do not consider it needful to let students know the benefits that could be derived from the study of mathematics beyond being a necessity for entry into colleges, polytechnics and universities. Unless students are exposed to the many uses of mathematics and of mathematical knowledge, they may never come close to realizing it. Considering that most people (students inclusive) find it difficult to give time and attention to anything they have not seen the value that would be derived from it, some students may only be paying lip service to the study of mathematics if teachers do not make known to them the importance of mathematical knowledge. Their focus would then be on acquiring a good grade in the subject at the end of their secondary school career whether by fair or foul means. The implication of this is that examination malpractice would be on the increase and a greater majority of the students would always fail the subject each year and so end up forfeiting the pursuit of many careers that would have benefitted them and the country better. More importantly, they would also be losing out in acquiring the basic knowledge, skills and habits that effective mathematics learning is expected to equip students with so that they can live a more meaningful and productive life in the society.

\section{Importance of Mathematics and Nigerian Students' Attitude Towards the Subject}

\subsection{Importance of Mathematics}

Every individual require the knowledge of mathematics to function effectively and efficiently in today's world irrespective of his/her job or profession. Daily, people are confronted with varied demands for mathematical competence. The housewife for instance frequently needs halving, doubling or tripling recipes consisting of such measures as $1^{1 / 2}$ cups, $1 \frac{1 / 4}{4}$ teaspoon, $3 / 4$ cups etc. She also needs to prepare family budget for food and other items that would be needed in the house. She needs to compare costs and decide which article to purchase and which not to. All of these situations require ample mathematical knowledge for wise decisions to be made.

Nurses or Medical personnel have a lot to do with mixing substances of different strengths. They therefore should know relative sizes, volumes, weights and capacities of bottles. Business men and women also make considerations about fast selling goods to purchase and decide on price cut for slow moving items. Besides, they study increase in sales as a result of advertisement and compare that with the cost of advertisement. The bus or truck driver, carpenter, painter, brick-layer, gardener, farmer, etc all have to put up with a lot of mathematical processes on quantitative situations. The value of mathematics in all fields of learning such as engineering, medicine, architecture, agriculture, etc., can also not be over emphasized.

Mathematics encourages the habit of self-reliance and assists learners to think and solve their problems themselves [2]. All mathematical topics, beyond computational skills, also have one good habit or trait they inculcate to the students. Topics in geometry, for instance, demand some amount of logical reasoning and analytical thinking from individuals so that they can be able to establish a relationship between known and required facts. Such topics and others in algebra help people to reason logically and to realize that facts can be utterly established, and so consequently develop the habit of desiring and demanding that in their affairs with others. Proofs also help learners to reason deductively and so are able to apply that knowledge in deducing the cause/effect of things that happen around them and within their environment. They can therefore react with understanding, for instance, to claims made by the media, their leaders or even the government on any issue.

Furthermore, mathematics is an exact and precise body of knowledge. The procedure by which the final answer is arrived at may be different, but the answer remains the same. There is therefore no half truth in mathematics. A statement is either true or false and an answer is either correct or not correct and can be verified by a reverse process. Accuracy and exactness are thus the pillars on which mathematics stands. It is a subject that cannot be learnt through vagueness of thought or argument. It therefore trains and disciplines the mind. A student of mathematics learns the value of accuracy and adopts it as a principle of life. Knowledge of mathematics, thus, promotes the habit of accuracy, logical, systematic and orderly arrangements of facts in the individual learner [2]. Mathematics equally helps to develop proper moral attitude in individuals as there is no place for biased feelings, no place for dishonesty and it trains people to observe rules, respect procedures and value time.

In mathematics also, learners are challenged to make discoveries of mathematical relationships. These discoveries lead them to analyze and interpret their experiences and to make generalizations which they can subsequently apply in new situations. Mathematics equally exposes learners to different ways of solving the same problem. So, the ability to tackle real life problems through different procedures is a habit that is acquired with the study of mathematics.

Commenting on the importance of mathematics, [3] stated that mathematics is the one skill everyone needs to 
master in life. According to him, even if it is the only one, one will at least be able to live without being cheated, robbed or abused. In his view, people need mathematics in their everyday lives and cannot live or survive without it, as just doing the basic essentials is dependent on one's ability to do mathematics.

So, apart from the importance of higher level mathematics in bringing about the realization of the goals of science and technology for a country, mathematics taught at the lower levels of Nigerian educational system are also there to help build reasonable, thoughtful and productive citizens. Emphasis on sound mathematical knowledge for pupils and students in primary and secondary schools is therefore for them to be able to reap the benefits of the acquisition of mathematical skills, live a better life and also be in a better position to directly or indirectly contribute to the development of the society and to the world's economy [4].

\subsection{Nigerian Students' Attitude towards Mathematics}

It is particularly disappointing to find that mathematics has remained one of the least successful subjects in Nigerian schools despite its importance, and also despite the time it receives in an average school system. Many students have the obnoxious notion that mathematics learning is an unattainable task. Not many school children have interest in the subject even right from the primary school level. A great majority of students believe that mathematics competence is reserved for a selected few. Unfortunately, many adults also share this same feeling.

It is common to have Nigerian adults declare their lack of competence in mathematics publicly without any feeling of shame whatsoever. Indeed, most adults with a little prompting tell how much they hated mathematics while in school and how they never did well in the subject. Why weakness in mathematics is thought not to be a problem or something anyone should be ashamed of is however an enigma. Perhaps it is because of the perception that majority of people fall within that group and so being among the majority is acceptable, or maybe because many people do not seem to realize the importance of the subject and of its knowledge.

With this kind of attitude towards mathematics displayed by the adult members of the society- parents, siblings and even some teachers, people that should be the ones to call the students to order, it is therefore not a surprise that students continue to display lack of mathematical knowledge and perform poorly in examinations in the subject especially in the West African Senior School Certificate Examination (WASSCE), taken after secondary education. [5] presented a statistical analysis of students' performance in mathematics in WASSCE conducted between 2000 and 2006, data they obtained from the WAEC Department of Research and Statistics, and it showed that no year recorded up to $40 \%$ credit pass throughout the period in question. A more recent analysis presented by [6] which covered up to 2011 also showed that students' performance has not yet significantly improved. The percentage of students that passed the subject at credit level from 2007-2011 still fell between 30 and 47 percent except in 2008 that the percentage got up to approximately $57 \%$. This poor performance trend of students in mathematics is however not peculiar to Nigeria. [7] stated that many African countries face common problems of poor performance of students in mathematics and science education. Indeed, [8] reported that last year 224,635 of South African's matriculated students wrote mathematics and fewer than half of these $(43 \%)$ passed with at least $30 \%$, less than $20 \%$ scored $50 \%$ or more and they described the situation as a cause for concern. [7] consequently stressed the need for African countries to strengthen the capacity of teachers to teach mathematics and science effectively.

\section{Mathematics Teaching/Learning}

\subsection{The Mathematics Teacher}

A whole lot of difference in the teaching and learning of mathematics can however be made by the mathematics teacher. A committed teacher of mathematics can surely turn around the sad story of mathematics learning in schools for the better. Usually, people point to a mathematics teacher they had at one stage or the other of their educational career as their reason for losing interest in mathematics. It therefore goes to prove that mathematics teachers can 'do' and 'undo' in the learning of mathematics. A dedicated mathematics teacher should be able to lift his/her students to the level they would begin to appreciate mathematics, its beauty and its application so that students' attitude towards the subject would begin to change and their performance in the subject consequently would also improve.

However, the problem is that many people have the erroneous notion that anybody can be a teacher. Well, anyone can actually teach but not everyone can teach well. There are certain qualities a mathematics teacher must possess and certain strategies he/she must adopt if he/she wants to succeed. Some of these qualities include:

\subsubsection{Mastery of Subject Matter:}

A mathematics teacher must acquire during training a good knowledge of the subject matter since no one can give what he/she does not have. This is very important for both primary and secondary mathematics teachers. That way such a teacher would be able to direct the students more competently and confidently. $\mathrm{He} /$ she can as well be able to simplify tasks for students and would be in a better position to present facts from different angles. A display of subject incompetence by a mathematics teacher causes the students to lose confidence first in the teacher and then in the subject.

\subsubsection{Building Students' Confidence:}

A mathematics teacher should be able to build the confidence of his/her students. According to [9], confidence begets attention which begets rich learning. Many students do not trust their ability in mathematics and this is where their problem begins. The teacher should therefore be able to convince them that they can do well in the subject. One way to build students' confidence is to provide them with challenging but attainable tasks and help them to make progress. The teacher should also applaud students' little efforts and should have positive expectations of each of them at all times. 


\subsubsection{Good Sense of Humor:}

A Mathematics teacher that wants his/her students to succeed must have good sense of humour. Students do not learn much by sitting still and looking frightened. They learn better in a relaxed atmosphere and when the learning experiences are pleasurable ones. In fact, students really like a teacher who can douse tension and make classroom activities interesting and enjoyable

\subsubsection{Encouraging Discussion:}

In a typical mathematics class, most talk comes from the teacher and seldom from the students. The students only pay attention or pretend to do so, copy notes, practice what the teacher has demonstrated, and then work individually to solve problems. None of these makes learning exciting and adventurous for students than conscientious argument and discussion. Argument in search of facts is the real meaning of the mathematical process. It can be learned only by doing and not by listening. So, communication with peers or teamwork is a very effective way of learning mathematics and must be encouraged. A mathematics teacher must therefore allow students talk with themselves in class and also freely talk with him/her as well

\subsubsection{Diversification of Learning Experiences:}

People say: Monotony kills interest, Variety is the spice of life'. Psychologically, children (and even adults) have limited attention span and can easily lose interest after a certain period of time and turn attention to something else. Good mathematics teachers vary learning experiences and teaching behavior during a classroom session to generate and sustain students' interest. They are lively, dramatic and demonstrative as against sedentary teachers who are inactive and make their lessons dull.

\subsubsection{Use of Effective Methods of Teaching:}

Based on past experiences of generations of teachers and of psychological analysis of intellectual processes and also based on research results, there abound a number of fairly unwavering teaching methods that mathematics teachers can use for effective instruction. However, it has been widely accepted that there is no 'best method' of teaching. A successful teacher especially of mathematics must therefore of necessity use several methods in one lesson. Various methodologies used in mathematics teaching include.

- Play-Way Method

- Project Method

- Demonstration Method

- Discovery Method

- Guided inquiry Method

- Problem Solving Method

- Laboratory Method

- Cooperative Learning Strategy

- Individualized Instruction

- Team Teaching

- Target Task Approach

- Computer Assisted Instruction

- Multiple Intelligences Teaching Approach

\subsubsection{Use of Instructional Resources}

Instructional resources are those resources (human and material) that are used to stimulate and maintain students' interest in mathematics learning as well as facilitate their understanding of mathematical topics. They help in the formation of concepts in students' minds. Mere telling without exposing the learners to the concrete materials does not enhance learning. A creative teacher therefore needs to know what materials are available or can be provided to enrich the teaching and learning of mathematical concepts.

\subsubsection{Set Induction}

Set induction is any pre-planned action of the teacher to arouse the interest of the students before a lesson. It is a way to motivate the learners and get them mentally set for a lesson. People say: Well begun is half done. Studies have shown that the activities preceding a learning task influence the performance of the task [10]. It is therefore vitally important to carefully plan the set induction of a mathematics lesson. There are innumerable possible approaches to it and every teacher is free to determine his/her own approach. However, the following approaches can be adopted singly or in combination to set induct students in a mathematics class:

- Opening of some bizarre packet

- A short story- True life or Fictional

- Dramatization

- Demonstration with an apparatus or tool

- An unusual behavior

- Use of creative questions

- Reference to a past experience of the students

- Inviting an expert in a field to class

- Some quick rearrangement of the class

- Specification of the instructional objectives of a lesson, etc.

\subsection{Best Practices for Mathematics Instruction}

A best practice is a way of doing something that produces the desired results. In the teaching of mathematics, a best practice is a teaching strategy or a way of organizing lessons that boosts students' understanding of mathematical concepts. Mathematics educators $[1,9,11,12]$ agree that to effectively teach Mathematics, teachers need to:

\subsubsection{Introduce Each Lesson by Relating Its Content to Students' Lives}

Relating mathematical contents to real life situations help students see mathematics as a way of solving their life problems and so a thing that deeply concerns them. Therefore, students should be led to see how what they are to learn directly applies to their lives. Word problems should be constructed based on the immediate environment of the learners and the activities that happen around them. Names used should be common names found within the society.

\subsubsection{Break Procedures Down into Minute steps}

Breaking Mathematical tasks down into steps and letting students learn each task step by step makes it easier for the students to understand better and enables a teacher 
find out specific points where students are having difficulty and may need help. According to Mighton in [9], no step is too small to ignore since mathematics is like a ladder that if one misses one step, he/she may not be able to go on.

\subsubsection{Teach with Songs, Games and Drama, and Permit Flexibility in How and Where Students Learn}

Many mathematical concepts can be taught with songs and games and many others can be dramatized in class and students enjoy it all. Topics like Numbers, Locus, Areas, Volumes, etc fit into this group. This way, all students would be lured to learn and to remain involved in what they are being taught. Moreover, a good mathematics teacher must always come up with other ways of presenting lessons and the students must not be confined to a particular place to learn.

\subsubsection{Lead Students to Derive Rules and Not Memorize Them}

The problem many students have with Mathematics is that there are many rules to be memorized. Rules should not be memorized. Rather, students should be led to derive the rules. That way, they will always remember them.

\subsubsection{Use Models, Pictures, Drawings, Graphics and Charts in explaining Mathematical concepts and relations}

Some individuals feel very uneasy with the study of mathematics simply because they cannot digest facts and figures in written form. Gardner in [13] noted that some people's strength intelligence is Visual-Spatial intelligence which gives them the unique ability to think in images and pictures and to visualize accurately and abstractly. For such people, pictorial presentation of information is the only easy and interesting way to comprehend any information or task. This view was corroborated by [14] who stated that visual evidence not only stimulates interest, but helps to build mathematical meaning. It also, they noted, promotes and supports the classroom spirit of inquiry and problem solving.

\section{Conclusion}

Mathematics is not a subject to be toyed with by any individual that wants to be productive or any nation that strives for scientific/technological development [6]. Nigerian children's poor achievement in the subject as evidenced in the analysis presented by [5] and [6] is indeed worrisome just as it is for many other African countries [7]. This therefore calls for immediate action or the country would be trailing behind many others scientifically and technologically for not adequately equipping its citizens with mathematical knowledge and skills. [7] pointed out the necessity of transforming mathematics lessons from teacher-centred to learner- centred and the need to make mathematics learning meaningful for the students. Children in Nigerian primary and secondary schools if properly guided to discover the beauty of mathematics can learn mathematical concepts with maximum understanding. The problem however is that very early in their school lives, many children get the impression that mathematics is an abstract and difficult subject reserved for a selected few with 'magic' brain as confirmed by [1], and as far as the children are concerned, no one has been able to disprove this.

A dedicated mathematics teacher however can turn this story around and show as Mighton emphatically stated in [9] that any child can learn mathematics at a very high level.

\section{References}

[1] Harbor-Peters V.F.A (2001). Unmasking some aversive aspects of school mathematics and strategies for averting them. Inaugural lecture, University of Nigeria, Nsukka. Enugu: Snaap Press Ltd.

[2] Adedayo, O. ( 1997). Mathematics phobia, diagnosis and prescription. National Mathematical Centre $1^{\text {st }}$ Annual Lecture, Abuja.

[3] Kravitz, C. (2013). Why math is important. Retrieved on $10^{\text {th }}$ July 2013 from www.slideshare.net/chelsea kravitz/why-math-isimportant.

[4] Anaduaka, U. S. (2010). Acquisition of mathematical knowledge for sustainable development: Implication for teaching and learning. In Talla, N.S., Mohammed, M. H., Apara, S. A. E. and Ogungbe, E. O.[Eds]. Education for Sustainable Development in Nigeria. A Publication of the Faculty of Education and Arts, IBB University, Lapai, Niger State. 237-247.

[5] Kurumeh, M. S. and Iji, C. O. (2009). Improving students' achievement in solving algebraic word problems using aesthetic value approach. Abacus. The Journal of the Mathematical Association of Nigeria, 34 (1) 37-45.

[6] Anaduaka, U. S. and Okafor, C. F. (2013). Consistent poor performance of Nigerian students in mathematics in senior secondary certificate examination (SSCE): What is not working? Accepted for publication in Journal of Research in National Development 11 (1) June 2013.

[7] Japan International Cooperation Agency (2012). Strengthening of mathematics and science education-Western, Eastern, Central and Southern Africa. Retrieved on 23rd July 2013 from www.jica.go.jp/../project05.html.

[8] Contract Accountants (2012). South Africa's poor mathematics results: What is the solution? Retrieved on 23rd July 2013 from www.contractaccountants.wordpress.com/2.

[9] Bornstein, D. (2011). A better way to teach math. Retrieved on $6^{\text {th }}$ June 2013.

[10] Eze, D. (1984). Finger prints on microteaching. Unpublished Lecture Material. Anambra State College of Education, Awka.

[11] Burke, K. and Dunn, R. (2002). Teaching math effectively to elementary students. Academic Exchange Quarterly. 6 (1).

[12] Protheroe, N. (2007). What does good math instruction look like? Principal 7(1)51-56.

[13] Chau, M. Y. (nd). Connecting learning styles and multiple intelligences theory through learning strategies: An online tutorial for library instruction. Retrieved February $4^{\mathrm{TH}} 2005$ from www.libres.curtin.edu.au/libres16n1/chau.htm.

[14] Ale, S. O. and Adetula, L. O. (2010). The national mathematical centre and the mathematics improvement project in nation building. Journal of Mathematical Sciences Education. 1(1)1-19. 